\title{
Forecasting potential innovation activities in high-tech industries triggered by merger and acquisition deals: a framework of analysis
}

\author{
Elena Aminova ${ }^{1}$ (iD \\ Received: 11 April 2016 / Accepted: 6 August 2016/Published online: 25 August 2016 \\ (C) The Author(s) 2016. This article is published with open access at Springerlink.com
}

\begin{abstract}
Technologies arising out of successful high-tech mergers and acquisitions (M\&A) have a significant innovation potential. However, forecasting of the possible output is coupled with uncertainties caused by misleading or insufficient future-oriented analytics. The proposed framework facilitates publicly available information and data to forecast potential innovation activities of the companies involved in hightech M\&As. A five-step scheme of analysis is aimed to assess previous M\&A record, intellectual property (IP) portfolios of the focal companies as well as the relevant technological context, and construct pathways of potential innovation activities using elements of a scenario technique and roadmapping. The framework has been tested on the deals including both large concerns and small and medium-sized enterprises (SME). We summarize the paper by reflecting on the merits and limitations of the framework on the way to our objective - to provide grounded forecasting triggered by M\&As to support the decision-making.
\end{abstract}

Keywords Technology forecasting $\cdot$ High-tech mergers and acquisitions · Innovation activities · Technology assessment

\section{Introduction}

Dealing with technology forecasts and anticipation of upcoming breakthrough technologies is one of the key tasks for those involved in technology-intensive industries. A question that is of particular interest for strategy experts/ management is

Elena Aminova

eaminova@zedat.fu-berlin.de

1 Furkastr. 83, 12107 Berlin, Germany which emerging technologies are worth investing in to reach the desirable synergy effects and extend the existing capabilities. However, nearly all investments in technology-driven industries are coupled with considerably high risks and uncertainty in terms of return on investment, time-to-market and resources required, compatibility with existing solutions, post-merger failure of the target company and product scalability. Since mergers and acquisitions (M\&As) are commonly understood as a "quick" way to source technologies [1] and may have a disruptive impact on the future competitive landscape [2], the problem of the validity and legitimacy of prognoses made on the basis of these deals becomes highly vibrant.

Over the past decade technology-driven sectors have experienced an intensified pace in merger and acquisition activities: several concerns almost simultaneously started aggressive expansions into other business sectors trying to acquire companies outside of their "traditional" markets [3-5]. Business analytics explained these activities either by intensified market dynamics or by shifts in the corporate strategy, and strived to predict the "next moves" of acquirers and new technologies that would face the market soon after the deal [6]. Speculations in the press about the potential outcome are obviously driven by the wish to foresee the dynamics of evolving markets. However, unless explicitly reported by the involved parties, the grounds for the transaction remain unknown. The innovation management has developed several approaches to describe and understand the grounds, drivers and dynamics of technology push through technology sourcing [7-15]. Still, this line of research is imposed to a failure risk due to its highly structured straightforward way of seeing the future [16]. On the other hand, a vision-focused perspective of Futures Studies might contain the risk of "missing the point". Therefore, there is a need for a weighted scheme of analysis that would allow for the grounded assessment of 
potential innovation activities triggered by M\&A deals with due regard to existing images of the future in the respective sector.

This paper presents a framework that addresses the above issues and may be used by practicing M\&A experts, as well as researchers, to analyse innovation systems in order to uncover synergy potential and visualize possible avenues of technological development. The contribution of our paper is twofold. First, we combined the tools of innovation management and Futures Studies in an enabling framework for a systematic analysis of existing capabilities, identification of the underlying technological potential of the deal and assessment of possible trajectories of technological development. Second, the proposed scheme of analysis unfolds existing images of the future (corporate and external) in a specific technological field that can be considered while building technological projections.

The paper has the following structure. In "Development of the analytical approach" section, we describe our view on M\&As in the high-tech industry, uncover the need for an interdisciplinary research of the interrelationships between M\&As and upcoming innovation activities and explain how our framework was developed. In Section 3, we outline the forecasting framework. In Section 4, we illustrate the framework by two case studies. Section 5 sums up the conclusions, limitations and draws the avenues for further research.

\section{Development of the analytical approach}

\section{Sourcing technologies through mergers and acquisitions}

Over the past 40 years the high-tech industries have seen several waves of merges and acquisitions [17, 18], each of which has reshaped technology-driven industries and set up the basis for subsequent market development [19]. During this period the image of a tech M\&A has shifted from extraordinary activity to business development routines [20]. Although M\&As as an economic, business and cultural phenomenon have been well studied [21], researchers emphasize that due to complexity of involved processes as well as internal and external uncertainties in the post-merger phase the M\&A failure rate remains high [17]; merging activities might entail significant risks and costs for the involved parties [22]. Researchers increasingly tend to appeal to the transdisciplinary character of problems arising out of in-sourcing technologies and use multiple scientific discourses to analyse M\&As [23, 24].

A majority of high-tech M\&As is deemed to create economic value by extending existing capabilities [22, 25]. M\&As as a way to source technologies can grant the acquirer considerably high benefits (as compared to "organic" growth) and evoke innovation synergy effects in both merging companies [26], provided that the acquirer has developed a pattern of activities, guidelines and policies used throughout the entire M\&A cycle [27, 28] and has enough resources to develop a sourced technology. As a rule, target companies are underfinanced start-ups that possess technology expertise and capabilities but lack financial prospects [29]; these investments seem to be more attractive in comparison with expenditures for acquirer's domestic R\&D. However, the acquirer faces the risk of low innovative outcome in the post-merger phase [22].

The scientific literature represents two distinct empirically proven positions on the relationship between merger and acquisition and technological output of merged companies. The first one suggests that there is a direct relationship between the grade of innovativeness of a target company and the positive post-acquisition $R \& D$ performance of acquirer [7, 22]. This view is underpinned by an increasing attention to the intellectual property as an intangible asset [26], especially when competences of a target company play the key role in determining the firm's real value [21]. In this case both inputs and outputs of the company are knowledge-based and the need to replenish the knowledge base becomes the basic driver for new acquisitions [30]. More precisely, a considerable part of high-tech M\&As are driven by the need to gain a special type of knowledge - technological knowledge [31-34]. It is not a ready product that can be sold or purchased; however, in a complex and rapidly changing industrial context acquisitions are the way to retain flexibility in sensing and seizing opportunities at lower costs [35]. Note that the major challenge that partially explains high failure rates in technology-driven M\&As is inability to adequately absorb and transfer knowledge of the target company [17, 24, 28, 31-33].

The second view argues that due to agency problems [36], lack of integrative decision-making [37], disruptiveness of routines [38], cultural clash [39], style of management [8] and discrepancies in corporate perception of the future [36] the post-merger output may be considerably lower than expected. Failures in integration in the later stages lead to underperformance and affect the extent and quality of innovative products, patenting activity and motivation of R\&D personnel of the target company.

\section{Unveiling corporate images of the future}

An important clue in understanding the intrinsic knowledge drivers and barriers are company's values and self-perception of its future. Surprisingly, M\&A activities in the context of corporate vision, mission and philosophy have been poorly researched in scientific literature. Peršič and Markič have studied the relationship among a company's vision, its strategy and social responsibility and found that there is dependence between social responsibility factors and successful corporate operations such as revenue, profit, and corporate operations [36]. We assume, first, that a company's vision, values, 
philosophy and mission statement can build a foundation for successful absorption of knowledge. Second, insofar as explicit technological knowledge is codified and publicly available on global data banks (such as patent data banks), it is possible to identify, analyse and reconstruct hidden corporate images of the future to which the above knowledge might contribute.

The need to formulate corporate images of the future has long been channelized through the term "strategic fit" [40]. However, later research in corporate foresight and Futures Studies revealed a set of fallacies in the classical view on a linear and "predictable" future [21, 41-43]. Over and above, the concept of "strategic fit" cannot explain high failure rates of M\&As, especially those resulting from incapability to integrate and absorb acquired knowledge [17]. The post-classic view on innovation activities admits the existence of multiple possible futures and considers innovation in the context of corporate micro- and macro-environment, current needs, organizational structure etc. Therefore, explanations and setting company's moves in line with other activities are often made ad hoc and ex post; this being said, a single "deliberate" strategy turns out to be useless and in some cases even harmful [44].

The latest generation of scientific studies addresses corporate images of the future - intrinsic motives, drivers, forms, types, dimensions of future discourses, handling with risks and uncertainties that bring a company on the way to perceive the future $[16,45,46]$. The notions of this approach will be used in our paper twofold. First, since images of the future are understood as meaningful representations about potential course of events and developments [45] that organizations make to reduce uncertainty these images could be used as a reference source while reconstructing company's intents. Second, insofar as mergers and acquisitions can be considered as mindful and deliberate acts targeted to extend company's future handling options, they represent the vision of at least one involved company about the development in a given field thus unveiling possible synergy of the deal. In this sense each M\&A deal shows a distinct intention to move towards a goal that often remains undisclosed to the public. Therefore, M\&As can be interpreted as a type of corporate images of the future.

\section{Existing approaches in forecasting technology futures}

While innovation activities resulting from a merger are marked with high uncertainty [10,47], insufficient research has been devoted to forecasting of the potential outcome of the deal. At the same time, much research focuses on a broader need to forecast technology future and anticipate effects of technological change on the market, adoption, diffusion and use of technology [48, 49].
Over the past decades technology forecasting has experienced its ups and downs, from regrets that this domain remains 'underdeveloped' outside the United States [50] to renewed interest with the focus on innovation and solid scientific opportunities [48]. The academic literature is represented by two distinct views on technology forecasting. The classical view treats technology forecasting in the context of a corporate plan [51]. Following this discourse, Watts and Porter showed that grounded forecasts could effectively synthesize a number of bibliometric methods, such as analysis of technological trends in combination with visualizations of technological interdependencies and competitive intelligence survey [52]. Organizational forecasting as a combination of statistical and judgmental forecasts showed good results in different application fields in the mid- and long-term perspectives [53].

In the corporate practice technology forecasting often serves as a part of strategic and technology management in its operationalized and simplified form - as technological roadmaps. Initially, roadmaps were meant as a planning tool that helps visualize technological developments and identify uncertainties and possibilities on the way to a target technology $[40,51]$. Over time roadmaps have evolved in a prediction and forecasting tool $[54,55]$ and were widely used to embed business and technological strategy into the front-end of the product development [56]. Although roadmaps are highly appreciated in the industry as a customizable tool that enables for forecasting of future technology dynamics by extrapolating trends based on either exploratory or normative approaches, the users should not forget that they simplify technology emergence and may fail when confronted with reality. This fact has a number of negative implications that restrict functionality of roadmaps in the context of technology forecasting. First, roadmaps have a linear structure and provide an illusion of predictability of the future [54]. Second, they typically consider only existing and/or anticipated options at the moment of their creation. Third, roadmaps as a type of the text represent a subjective, personalized view of their creator on technology dynamics. Finally, this forecasting method is deterministic by nature and therefore contains a potential of becoming a self-fulfilling prophecy and as such may become a trigger in forming of an undesired path [56].

The second view on technology forecasting has emerged in a wish to shift away from the deterministic planning paradigm and equip strategic management with an intelligence tool providing grounded insight about potential technological changes $[52,57]$. It assumes that early technology emergence involves findings and inventions from previously non-related industries [12]. To be able to grasp possible technological linkages Roninson and Propp propose to analyse emerging technologies by assessing the impact of technological alternatives on an end technology [13]. This approach has two general merits: it manifests the probabilistic character of roadmaps and provides a reflexive view on possible technology development 
with due regard to technological context and market environment. Building on this view Robinson et al. developed an enabling framework to visualize possible innovation pathways for selected technologies [12, 14, 15]. The authors stress that pathways may and often do have a nonlinear character; to reveal the complexity of the product it is necessary to consider business and technology environment, deploy quantitative empirical technology forecasting methods to explore subtechnologies originating from non-related industries [58], capture early signals of possible commercial application and consider uncertainties on the way to societal embedding [15].

\section{Analytical framework}

This paper presents the framework that focuses on the analysis of potential future outcome of high-tech M\&A deals. As we proceed, we will synthesize the tools and approaches of innovation management and Futures Studies in order to cover flaws of the above-mentioned methods. The deals will be analysed from the perspective of possible benefits for the involved companies. We will integrate companies' visions, mission statements and other relevant internal policies while constructing the pathways in order consider possible internal discrepancies that might lead to post-merger failures. Considering these documents is also important to correctly define the outcome technology. To avoid determinism and open up a perspective on a number of technological possibilities we will present a set of pathways on a way to a target technology. We will be building on assumptions that innovation pathways have a probabilistic character and may omit the technologies that have not been explored yet. This holistic approach also helps us to embed the output technology into a broader context and get insights about functionality that might be added later during the research and development phase.

Our framework is designed to provide an outside-in analysis of possible innovation activities based on reported M\&A deals. The approach facilitates publicly available information about the deals, IP portfolios of involved companies and research of the respective technological context. This implies three criteria. First, both acquirer and target should possess their own IP portfolios. Second, the information about activities of the focal companies must be publicly available. Third, there must exist a scientific discourse related to the focal technologies. In this framework, we deliberately avoid using expert workshops, since expert opinions - though providing detailed information and insights - may restrict the horizon to the fields of their competence and interest [59].

The proposed framework contains five steps (Fig. 1). The first and second steps involve setting the technological context for the acquirer and the target to uncover the record of technologies sourced through M\&As in order to reveal existing $R \& D$ paths. These steps are required to assess possible technological synergy for the focal companies. The third step is tailored to open up a perspective on potential avenues of development in a given field. With this purpose the speculations about the deal in mass media will be supplemented by normative connotative discourse, as appearing in companies' mission statements, philosophy and other policies. Further, the dynamics will be observed from the perspective of genesis of technologies. By doing so we address two pending questions: does a potential technological trajectory "fit" into the normative paradigms of the focal companies; how could the possible technological output look like. Opening up a perspective on the genesis of technologies implies the need to identify alternative solutions and consider correlations among them in the pathways. To avoid incompatibilities while constructing pathways the raw roadmapping step must be preceded by cross-impact analysis. It should be noted that for reasons of simplicity, we included only the open technologies (sub-technologies on the way to a desired technology, where neither the acquirer not the target has reported know-hows and/or inventions) into the final roadmap set. However, to get the holistic view it is recommended to consider all identified technologies. In the fourth step we determine the development grade of each sub-technology, identify possible correlations and interdependencies in a pathway, check whether the pathways go in line with the acquirer's vision and outline the trajectories of technological development. The last step implies presentation of results.

Further on, we will describe the analytical framework in detail. Note that the proposed structure is not rigid. The design of sub-steps may vary depending on the specifics, development grade and estimated life cycle of a focal technology, size of the engaged companies and industries they originate from, the business model and the strategic agenda of the acquirer.

\section{Step one: creating acquirer's profile}

This step involves elaborating the business profile of the acquirer in order to understand its business. We also considered the industry and sector(s) of operations to get an overview of its market environment. The company's reported revenue for the last three fiscal years is analysed to understand the growth dynamics; amount of research and development (R\&D) expenditures in their relation to the revenue help provide an overview of the acquirer's R\&D model. Large R\&D costs may evidence that a company prefers domestic R\&D to sourcing technologies externally. Information about shareholders, senior management and number of employees might be helpful to get an impression about internal hierarchies and levels of decision-makers. Analysis of regions of operations enables consideration of markets where the company leads its 

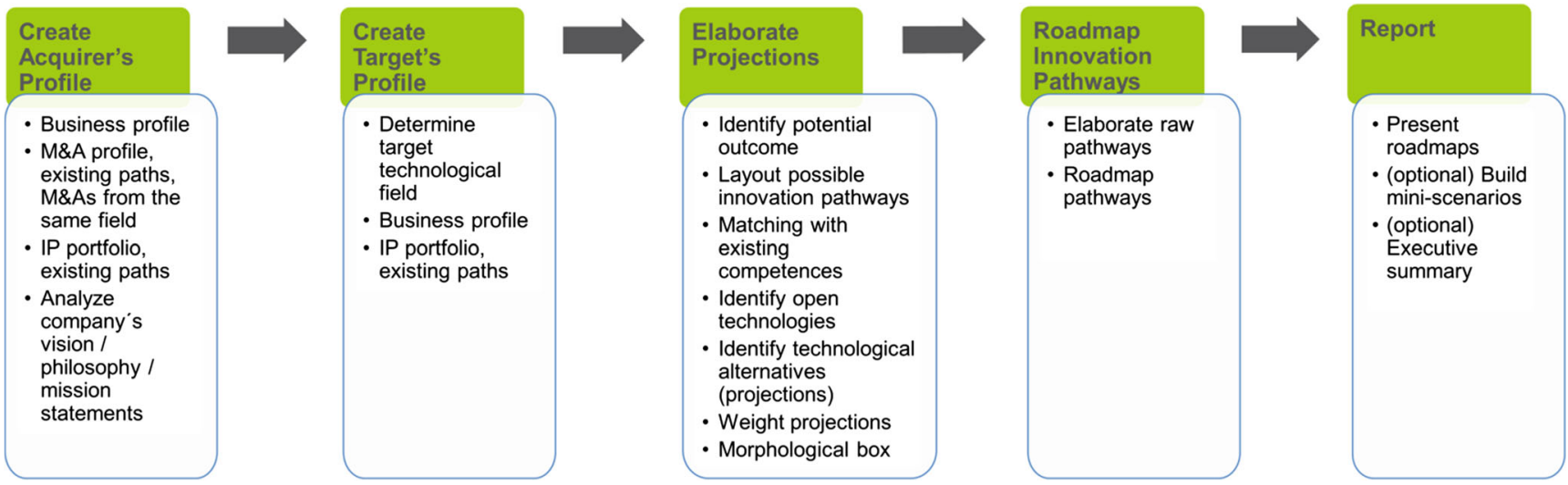

Fig. 1 Analytical framework to forecast potential innovation activities triggered by M\&A deals

operational activity (and might need to secure its intellectual property by patents). All the above-mentioned data will be collected from a company's Internet site, its financial statements, annual reports and official press releases.

In the following, the M\&A profile of the acquirer is outlined. This profile is targeted to show the extent of a company's activity in sourcing companies; the size, industry and country of origin of target companies; the character of acquisitions. Most strategic investments are normally made in companies from related industry sectors [19]. An acquisition from another sector ("non-related acquisition") might indicate the wish of the acquirer to enter a new market or extend its existing capabilities through new applications of technologies. It might also mean that the target technology is undergoing a growth stage where a successful diffusion is possible. We applied a qualitative media content analysis to assess information from mergermarket, ${ }^{1}$ an online analytic tool aggregating data about reported mergers and acquisitions. The business intelligence tool has been developed by economic journalists in cooperation with M\&A advisors and experts to provide analytics on M\&A deals and corporate strategy - in general based on global media content analysis, historical data and trend analytics by industrial segments. For the purposes of this research mergermarket has been used to illustrate the acquisition dynamics, reveal deal patterns and identify emerging paths in sourcing technologies by the focal companies.

The output of this step will be used, as follows: first, it can indirectly prove our thesis that companies operating in hightech sector prefer sourcing new technologies rather than developing them in-house, especially when it comes to expansion in the new markets and industries; second, it helps cluster acquisitions by industries and thus reveal existing and emerging M\&A paths; third, each acquisition record contributes to the acquirer's IP portfolio. Including company's affiliated structures into the search will further help us build the comprehensive search strategy for the IP portfolio. This being said, it is important to take into account alternative ways to gain

${ }^{1}$ www.mergermarket.com technologies, e.g. through open innovation, networks and cooperation, by outsourcing R\&D. If a company discloses any strategic partnerships, they must be considered and assessed respectively.

Once an M\&A record of the acquirer has been tracked, we can proceed with analysis of its $R \& D$ activities. In this paper we mainly refer to a company's IP portfolio. To extract patent data we used TotalPatent, the IP data bank by Lexis Nexis. ${ }^{2}$ TotalPatent is a comprehensive and up-to-date resource containing over 70 million full-text patent documents from the major patent authorities, including the US Patent Authority, European Patent Office, World Intellectual Property Organization, as well as the US American, Chinese, Japan, Korean, German, British, French and Canadian Patent Authorities. If a company's IP portfolio is considerably large, it might make sense to use software to visualize existing technological clusters. Unveiling company's IP portfolio is important to understand in which technologies it is currently active and has accumulated strong capabilities; this information, in turn, could be used to detect its existing R\&D paths [60]. At the same time, this step is intended to shed some light on possible upcoming innovations that could involve both company's own and sourced technologies and, therefore, unfold acquirer's intentions. In this research, we used the search strategy by corporate name of the acquirer and its affiliated companies (if any) to extract the IP portfolio and cluster documents attributing to the same technological field.

Finally, we analyse acquirer's vision, mission statements, philosophy and other relevant policies. This step is aimed, first, to integrate codified company's images of the future into construction of pathways and, second, to understand, whether a company consistently follows, retains and preserves its own values and philosophy while innovating or prefers to adjust its policies to conform to its current agenda. Bannert and Tschirky stated that an intensified pace of technological change together with growing technological complexity and short product life cycles force companies to shorten their plan-

${ }^{2}$ www.lexisnexis.com/totalpatent 
ning horizons to mid-term legislative periods, and source technologies externally (which explains the tactics of sourcing companies rather than raising them inside a company) [37]. However, this position contravenes the practices of numerous high-tech players that consistently develop long-term visions and normative future-oriented policies [61]. Note that peculiarities of the business sector might predetermine acquirer's vision and philosophy. First, visions usually bear a normative character; technologies, as described in visions are flexible and user-friendly, except those depicted in the "worst-case scenarios" where technique is opposed to and acts hostile towards human beings. Second, an appeal to evolutionary processes in technology helps both build a consistent narrative and avoid logical gaps [62]. Third, a wide range of marginal sources for new ideas, including science fiction, gaming, movies etc. is facilitated while constructing images of the future(s). Fourth, visions consider technological changes in the broader context, thus describing possible impact of evolving technologies on social, political and economic stability of the system.

\section{Step two: creating target's profile}

To start analysing the target we need to determine the technological field it originates from [15]. This step enables us to seize the specifics and dynamics of the sector where the sourced technology has emerged as well as consider internal and external factors that are likely to have an impact on the technological output. Special attention is paid to the actual challenges in the technological field, since solving one of them might be the motive of the deal. This step is based on a qualitative keyword-based analysis of scientific literature indexed on primo, a library search engine of Freie Universtät Berlin. ${ }^{3}$ The library resource contains thousands of online scientific documents (publications in peerreviewed journals, newspapers, books, conference materials etc.) covering the major findings for the last decades. In addition to the academic research, official press releases and profile information from the website of the target company are used.

Next, we elaborate the business profile of the target. The profile shall contain the information about the target's revenue for the last three fiscal years, its products, amount of $R \& D$ spending. Note also that target companies are often start-ups that do not generate profits. Therefore, traditional valuation methods (e.g. discounted cash flow analysis) to estimate returns on investment might be difficult to apply.

Further, we perform analysis of the target's IP portfolio to unfold its competences and know-hows. As in case with the acquirer, we use the search strategy by a company name to retrieve the data from TotalPatent.

\footnotetext{
${ }^{3}$ www.primo.fu-berlin.de
}

\section{Step three: elaborating projections}

On this step, we build projections of possible logically consistent trajectories of innovation activities triggered by an M\&A transaction. For this purpose, we use publicly available information in mass media about the deal [63], inputs about IP portfolios of involved companies and analysis of the respective technological context. In order to open up the perspective we applied tools and techniques that are traditionally used by Futures Studies in scenario construction.

We start by identifying the potential outcome of the deal. This step is performed with quantitative media content analysis in Google News. ${ }^{4}$ A secondary news aggregator has been chosen deliberately, since it embraces a wide variety of news and relevant press releases from around the globe. To extract the content key-word-based search strategies were built. The search was limited to include English sources only. Media content analysis has several advantages over expert-based approached that is traditionally used by Futures Studies: the ability to aggregate press releases from different countries combined with large amounts of information which otherwise would be impossible to produce in workshops.

Once the potential outcome is set, we can explore possible technological components. This step serves to determine the scope of the analysed technology (set of technologies) by "splitting" the output technology into sub-technologies, which are or might be required to achieve it. By doing so we answer the following questions: what sub-technologies might be required to develop the future technology; what is the development grade thereof; what might be the problem fields on the way to the above technology; have the identified subtechnologies already found commercial application (can they be treated as components or technological solutions requiring adjustment and in-house R\&D work).

Once the relevant sub-technologies are identified, they can be matched with existing capabilities (e.g. patents) from extracted IP portfolios. To do so, we compare the list of technologies above with technologies mentioned in the IP portfolios of the acquirer and/or the target. The goal of this sub-step is to identify the "open technologies" where neither of the companies possesses capabilities. For the focal companies it would mean that in order to develop the specific technology they might either need to initiate in-house R\&D projects or source the technologies externally.

Next, we describe the open technologies thus covering two practical issues. First, the open technologies are supplemented with definitions in order to avoid ambiguity in interpretation on the later steps. Second, it might be helpful to double-check the results to avoid overlapping with similar technologies from companies' IP portfolios. Once the open technologies are identified, "technological projections" for them must be

\footnotetext{
${ }^{4}$ www.news.google.com
} 
detected [48]. Opening up a perspective on technological alternatives is essential to provide decision makers with an outlook of the horizons of technological advancement, unfold possible avenues of development and report on functionality that could be added to the product. In addition, listing alternatives can help visualize critical underdeveloped areas represented by a single technological solution.

This step is performed using the key-word-based search in patent data banks and academic literature. Since the major part of open technologies is emerging, we limit the search in scientific record by research published in the last 10 years. A profile for each open sub-technology shall include information, as follows:

- Description of a technology;

- Number of patents registered for that technology;

- Number of scientific publications devoted to the technology;

- Technological alternatives or "projections" in gaining a technology with a short description thereof;

- Information about compatibility with other sub-technologies in a pathway;

- References and sources used for a profile.

In order to build logically consistent pathways we need to assess compatibility among technologies. Futures Studies traditionally propose three evaluation approaches: an intuitive logic that implies mechanisms of common sense in bringing projections together; trend-impact analysis appealing to the levels of significance and the current dominance of certain factors; cross-impact analysis weighting the impact and dependency of factors on another. This research applies crossimpact analysis, since it helps reveal and transparently document strict and minor technological correlations between projections [64]. In addition, cross-impact analysis can provide insights about functional synergies among sub-technologies. To evaluate the impact of technologies on each other the following scale is used: 2. Strict correlation between projections; 1 Projections suit well to each other; 0 Neutral correlation between projections; -1 Minor incompatibility between projections; -2 Projections are incompatible.

The resulting pathways must contain internal logics and consider the applicable sub-technologies. Morphological analysis is now getting increased attention from academicians and practitioners, since it enables to bring together all options for a pathway [65] without prioritizing any of them and to show compatibility among separate sub-technologies. During this step the technological projections will be summarized to build a matrix, which will later be used to construct raw pathways.

\section{Step four: roadmapping innovation pathways}

This step involves mapping raw pathways. A raw pathway is a set of technological findings and milestones with positive or neutral correlation that are required to lay out a possible innovation pathway. In this research we avoided matching technologies that have shown a negative correlation in crossimpact analysis. Creating raw pathways requires internal logics. As an "anchor" we have chosen one technological field that is believed to play the decisive role in design or functionality of the future technology. Therefore, the raw pathways represent three possible sequences of technologies compatible with the anchor technology.

To achieve plausibility raw pathways must be embedded into the corporate and technological context. For each set of pathways the time horizon is determined based on official press releases or interviews with officials of the focal companies. Projections are depicted as symbols to distinguish between technological components, mature technologies, technologies on an early stage of development. While preparing roadmaps it might be difficult to estimate timing for each R\&D project that might be required to develop a sub-technology. An expert workshop could help get a weighted overview on resulting roadmaps as a process.

\section{Step five: reporting}

The last step involves presenting the pathways: each pathway is accompanied with mini-scenarios that serve to highlight functionality, features and characteristics of the technology.

\section{Case studies}

To illustrate the framework, we report on two M\&A case studies; the first one - the deal between Google Inc. and Boston Dynamics Inc.; the second one - between GoPro Inc. and Kolor SAS.

\section{Case study 1: Google Inc. - Boston Dynamics Inc.}

The deal between Boston Dynamics Inc., a US-based robotics company, and Google Inc., a US-based IT concern was closed on December 10, 2013. Neither company has disclosed the purchase amount. Both parties to the deal possess their own IP portfolios and continue operating in the market under their original names. For Google, this was a non-related deal. We investigated the deal in the period from May to September 2015.

\section{Profile of Google Inc.}

Google Inc. is a large technology concern headquartered in Palo Alto, USA and operating throughout the world. It was incorporated in 1998 and is publicly traded since 2004. The company's core activity in the first decade was focused on providing internet-related products and services, such as 
online search, online advertising technologies, software and mobile application development and cloud computing. Of these business segments, ad technologies are generating most of concern's profits. ${ }^{5}$ Over the past decade the company has built a wide structure of project-related subdivisions clustered as "services for private customers", "services for companies" and "our contribution to a better web". In October 2015, Google became a subsidiary of Alphabet Inc. The parent company has been controlling Google's "traditional" businesses, while new Google is involved in projects that have been "far afield" of its mainstream projects.

The concern shows steady growth for the last years: its revenue for 2015 reached USD 74.54 billion (as compared to USD 65.67 billion in 2014 and USD 55.51 billion in 2013). With its total research and development expenditures exceeding $16 \%$ of its annual revenue in 2015 , Google ranks among the world's top promoters of innovations, is actively boosting its in-house R\&D along with sourcing technologies externally [66]. As a rule, the company does not disclose the reasons for its merger and acquisition activities; some experts believe that intellectual property is of prime interest for Google at the moment [67]. The concern's technological strategy owes its specifics to the industry it comes from: the IT sector is generally characterized by high innovation dynamics. Product life cycles are shorter than in other industries and the time factor plays a critical role. All that forces the market players to get increasingly engaged in open innovations or seek for start-ups with expertise in particular technologies or technology-based products rather than back their domestic R\&Ds and optimize business development operations [38]. Particularly, Google seeks to reach start-ups on an early stage and "refine" them within the company's R\&D. Most of the acquired companies contribute to the company's existing business segments. Robotics in its relation to IT technologies offers an interesting case to capture and visualize possible strategic and innovation twists.

By September 2015, the concern announced it had closed 182 M\&A deals, most of the targets have been start-ups. Along with Boston Dynamics, Google has acquired seven more robotic companies, most of which originate from legged robotics. Besides that, several clusters of deals represent growing interest of the company in the following technological areas: home automation business, artificial intelligence and semantic search business, robotics and cloud software.

Following this, in the first stage of the project, we analysed Google's IP portfolio. The data was retrieved from TotalPatent on June 9, 2015 using the key-word-based search strategy by assignee name, as follows:

ASSIGNEE("Google Inc.") or ASSIGNEE("GoogleAtlanta") or ASSIGNEE("Google-Boston") or ASSIGNEE("Google-Chicago") or ASSIGNEE("Google-

\footnotetext{
${ }^{5}$ See https://www.thinkwithgoogle.com/products/
}

Detroit") or ASSIGNEE("Google-New York") or ASSIGNEE ("Google-Santa Monica") or ASSIGNEE("Google-Seattle") or ASSIGNEE("Admeld Inc.") or ASSIGNEE("Adometry, Inc.") or ASSIGNEE("Boston Dynamics Inc.") or ASSIGNEE("DoubleClick, Inc.") or ASSIGNEE("DoubleClick Australia Pty. Limited") or ASSIGNEE("DoubleClick International Internet Advertising Limited") or ASSIGNEE("DoubleClick Techsolutions (Beijing) Co. Limited") or ASSIGNEE("eBook Technologies, Inc.") or ASSIGNEE("Google International LLC") or ASSIGNEE("Google Wallet") or ASSIGNEE("ITA Software, Inc.") or ASSIGNEE("Lumedyne Technologies Incorporated") or ASSIGNEE("Nest Labs, Inc.") or ASSIGNEE("Quickoffice, Inc.") or ASSIGNEE("Slide, Inc.") or ASSIGNEE("Teracent Corporation") or ASSIGNEE("Widevine Technologies, Inc.") or ASSIGNEE("Wildfire Interactive, Inc.") or ASSIGNEE("YouTube, LLC") or ASSIGNEE("ZAGAT Survey, LLC") or ASSIGNEE("Google Ireland HoldingsEurope, Middle East \& Africa Headquarters") or ASSIGNEE("Google Ireland Limited") or ASSIGNEE("Google France SarL") or ASSIGNEE("Google Germany GmbH") or ASSIGNEE("Nik Software GmbH") or ASSIGNEE("Nik Software, Inc.") or ASSIGNEE("Google Italy s.r.l.") or ASSIGNEE("Google Netherlands B.V.") or ASSIGNEE("Google Spain, S.L.") or ASSIGNEE("Google UK Limited") or ASSIGNEE("Google-Canada") or ASSIGNEE("Google-Greater China") or ASSIGNEE("Google-India") or ASSIGNEE("Google Australia Pty. Ltd.") or ASSIGNEE("Google Japan Inc.") or ASSIGNEE ("Waze Ltd.") OR STANASSIGNEE ("AUTOFUSS") OR STAN ASSIGNEE("REDWOOD ROBOTICS") OR STANASSIGNEE("INDUSTRIAL PERCEPTION")

According to the search results, Google and its affiliates possess a portfolio of 24,739 patents.

Several distinct technological clusters show the areas where the concern is striving to protect its inventions: advertising content; search query; image recognition; content predictive information; communication method; web content methods; video content, web applications and some minor fields.

The acquisition of Boston Dynamics Inc. was a non-related deal for Google. Google's mission provides the entrance point for looking for possible synergies. The company builds on the ideas of global connectivity, availability of information and interdependence ("overlapping") of physical and virtual worlds where communication technologies would catalyse political, social and cultural "breakthroughs" that are likely to reshape traditional forms and channels of information transmission. The moral implications of connectivity and information transparency on Google's operations are codified in its list of commandments [68]. 
The concept of global connectivity has a potential for the models of future interaction. Besides that, connectivity and information transparency are explicitly mentioned in Google's philosophy, which is summarized in a set of values - ten assumptions or "commandments" that govern Google's strategy and business processes. ${ }^{6}$ These instructions will further help us define the future products (as "images of the future") and build projections.

\section{Profile of Boston Dynamics Inc.}

The target company operates in legged robotics, a sector that is believed to grow in the next decade thanks to a number of technological breakthroughs: locomotion technologies have boosted the market of mobile robotics that has been growing for the last several years [69]; progress in engineering robotic components, e.g. actuators, extended robotic weight-lifting capabilities and speed of motion [70]; advancements in haptic technologies helped improve fine motoric capabilities [71]; techniques of obstacle avoidance allowed improving control over robotic motion.

Along with engineering advancements, legged robotics faces a number of challenges: achieving stability, development of balancing capabilities and adaptivity of robots to different surfaces; increasing speed of motion by optimizing the "perception-analysis-action" algorithm; creating advanced hand mechanisms enabling grasping of huge, tiny and sophisticated objects; equipping robots with long-life power sources, e.g. durable batteries; creating advanced robotic software allowing for deep learning. In recent years a trend has emerged to design and develop an "intelligent generation" of social robots capable of autonomous moving, decision-making, helping and interacting in "human-centered environments" [72].

Boston Dynamics Inc. is one of the world's leaders in building legged robots, most of which are designed for military purposes. The company was founded in 1992 and currently possesses several know-hows in creating agile, robust and fast-moving robots. Before its acquisition by Google, Boston Dynamics has reportedly cooperated with Defense Advanced Research Projects Agency (DARPA), the US Army, Navy and Marine Corps. The company's product line includes nine models of robots, all of which have different functionality and mobility. The company faces direct competition basically in the market of military robotics.

The patent portfolio of Boston Dynamics, Inc. contains 11 patents representing inventions in hopping robots, actuators, robotic legs, robot drive and brace system.

\footnotetext{
${ }^{6}$ https://www.google.com/about/company/philosophy/
}

Elaborating projections in deal Google, Inc. - Boston Dynamics, Inc.

To identify potential outcome technologies and/or products for the deal Google, Inc. - Boston Dynamics, Inc. we performed the quantitative media content analysis in Google News Aggregator using the search strategy, as follows:

((Google AND "Boston Dynamics") AND (future OR perspective OR envisage OR plan OR will OR wish))

For this search only sources in the English language were considered. The analysis session was performed on August 15,2015 ; ca. 11.200 hits have been identified in the following fields:

- Automated military robotics;

- Disaster relief;

- Social robots;

- Smart robots;

- Control over robots.

Further, we checked whether possible outcome technologies correspond to the vision, mission statement and philosophy of the Acquirer. Following that, we excluded "automated military robots" from further research, since this outcome contravenes basic Google's principles. The proposed framework can be used to build technological projections for each of the remaining technologies. We will illustrate the method by example of "smart robots" as a potential outcome.

Smart robots are cognitively inspired artificial robotic models and man-made systems. Based on the qualitative analysis of scientific literature published for the last 10 years and listed on Primo, we identified 29 sub-technologies for "smart robots" To prepare the list of related technologies we used the Layered Reference Model of the Brain (LRMB) proposed by Wang [73]. The sub-technologies were ascribed to one of the levels, as follows: sensation, memory, interaction, perception, meta-cognition, image construction and denotation, meta-inference, higher cognition.

Having identified the relevant sub-technologies, we analysed whether the acquirer or the target already possesses capabilities in any of them. For that, we compared technologies with the acquirer's and target's IP portfolios, as elaborated in "Profile of Google Inc." and "Profile of Boston Dynamics, Inc." sections above. After matching sub-technologies with existing capabilities we detected eight "open technologies" in which neither company has developed capabilities, as follows:

- Abstract thinking (or abstract intelligence);

- Generating emotions;

- Critical reasoning;

- Adaptability;

- Self-diagnosing; 
- Ethical decision-making;

- Proximity sensors;

- Smell sensors;

Once the open technologies are identified and supplemented with a brief description, the "technological projections" for each of them are explored. TotalPatent and Primo were used to search for technological solutions (Table 1).

Further, the impact of open technologies on each other and compatibility of technologies are assessed with cross impact analysis. We have revealed a general strict correlation between abstract thinking and critical reasoning. Other strict correlations were found between projections of self-diagnosing technology and adaptability, ethical decision-making and abstract thinking.

Following cross-impact analysis, the morphological box is built. Most of the open technologies have at least two projections. However, two of them; "Abstract thinking" and "Critical reasoning" are deemed underdeveloped. We presume that they will be enriched with new technological alternatives and have therefore included "alternative technologies" as options in the morphological box.

\section{Roadmapping raw pathways}

We used "abstract thinking" as an anchor technology for building raw pathways (Fig. 2). The three pathways constructed in correspondence with cross-impact analysis represent each the possible combination for smart robots using either imperative, autonomic, and cognitive computational intelligence (Pathway A, yellow line), the generic abstract intelligence mode (Pathway B, red line) or an alternative technology of abstract thinking (Pathway $\mathrm{C}$, blue line).

Based on technology sequencing in raw pathways, we constructed three potential innovation pathways (Fig. 3).

In setting the time horizon for "smart robots" we referred to Ray Kurzweil, Director of Google Engineering, who in his interview to the Guardian predicted that robots would excel their makers in intellect by the year 2029 [74].

\section{Reporting}

To report the innovation pathways we supplemented technology roadmaps with a short description.

Pathway A represents a smart robot that runs imperative, autonomic, and cognitive computational intelligence for abstract thinking. Most of its algorithms for cognitive processes have been designed in a way similar to those of a natural brain. It is equipped with ultrasonic sensors to detect obstacles; fusion-based gas sensors help it grasp and process even small amounts of odour. The robot uses cameras to capture visual information about the environment. Video sensors are also applied for self-diagnosing. The information about defaults

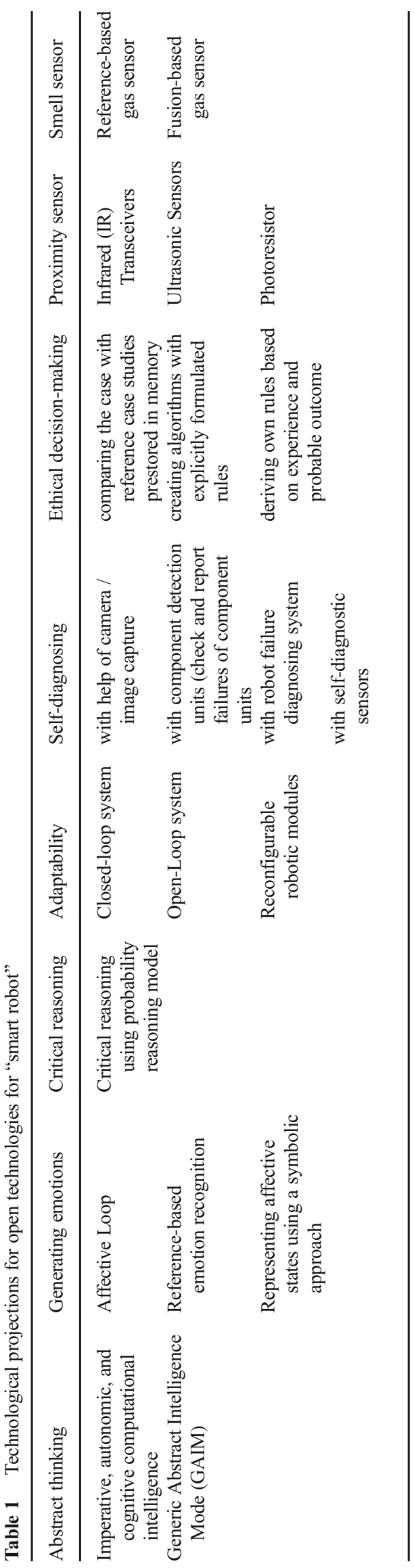




\begin{tabular}{|c|c|c|c|c|c|c|c|c|}
\hline & $\begin{array}{l}\text { 1. Abstract } \\
\text { thinking }\end{array}$ & $\begin{array}{l}\text { 2. Generating } \\
\text { emotions }\end{array}$ & $\begin{array}{l}\text { 3. Critical } \\
\text { reasoning }\end{array}$ & $\begin{array}{l}4 . \\
\text { Adaptability }\end{array}$ & $\begin{array}{l}\text { 5. Self- } \\
\text { diagnosing }\end{array}$ & $\begin{array}{l}\text { 6. Ethical } \\
\text { decision- } \\
\text { making }\end{array}$ & $\begin{array}{l}\text { 7. Proximity } \\
\text { sensor }\end{array}$ & $\begin{array}{l}\text { 8. Smell } \\
\text { sensor }\end{array}$ \\
\hline Projec. 1 & $\begin{array}{l}\text { Imperative, } \\
\text { autonomic, } \\
\text { and cognitive } \\
\text { computational } \\
\text { intelligence }\end{array}$ & $\begin{array}{l}\text { Affective } \\
\text { Loop }\end{array}$ & $\begin{array}{l}\text { CR using } \\
\text { probability } \\
\text { reasoning } \\
\text { model }\end{array}$ & $\begin{array}{l}\text { Closed-loop } \\
\text { system }\end{array}$ & $\begin{array}{l}\text { with help of } \\
\text { camera / } \\
\text { image capture }\end{array}$ & $\begin{array}{l}\text { comparing the } \\
\text { case with } \\
\text { reference case } \\
\text { studies } \\
\text { prestored in } \\
\text { memory }\end{array}$ & $\begin{array}{l}\text { Infrared (IR) } \\
\text { Transceivers }\end{array}$ & $\begin{array}{l}\text { Reference- } \\
\text { based gas } \\
\text { sensor }\end{array}$ \\
\hline Projec. 2 & $\begin{array}{l}\text { Generic } \\
\text { Abstract } \\
\text { Intelligence } \\
\text { Mode (GAIM) }\end{array}$ & & $\begin{array}{l}\text { Alternative } \\
\text { technology }\end{array}$ & & $\begin{array}{l}\text { with } \\
\text { comp } \\
\text { detect }\end{array}$ & $\begin{array}{l}\text { creating } \\
\text { algorithms } \\
\text { with explicitly } \\
\text { form lated }\end{array}$ & $\begin{array}{l}\text { Jltrasonic } \\
\text { Sensors }\end{array}$ & $\begin{array}{l}\text { usion-based } \\
\text { gas sensor }\end{array}$ \\
\hline Projec. 3 & $\begin{array}{l}\text { Alternative } \\
\text { technology }\end{array}$ & $\begin{array}{l}\text { Representing } \\
\text { affectiv } \\
\text { states using a } \\
\text { symbolic } \\
\text { approach }\end{array}$ & & $\begin{array}{l}\text { Recon } \\
\text { e robo } \\
\text { molul }\end{array}$ & $\begin{array}{l}\text { with robot } \\
\text { failure } \\
\text { diagnosing } \\
\text { system }\end{array}$ & $\begin{array}{l}\text { de iving ow. } \\
\text { rul bas d on } \\
\text { and probable } \\
\text { outcome }\end{array}$ & & \\
\hline Projec. 4 & & & & & & & & \\
\hline
\end{tabular}

Fig. 2 Raw pathways for "smart robot"

is then referred to the control centre and reported to the user enabling him/her to reconfigure robot's modules through the open-loop control system. The robot generates emotions affectively in response to the changing environment. It is capable of making critical judgements by estimating the probability of occurrence of a potential event. This functionality enables the robot to derive its own ethical rules based on its previous experience and probable outcome. This pathway requires no extra costs for long-lasting R\&D projects, however, the robot will not be capable of completely autonomous action (the functionality may be restricted in case of module damage).

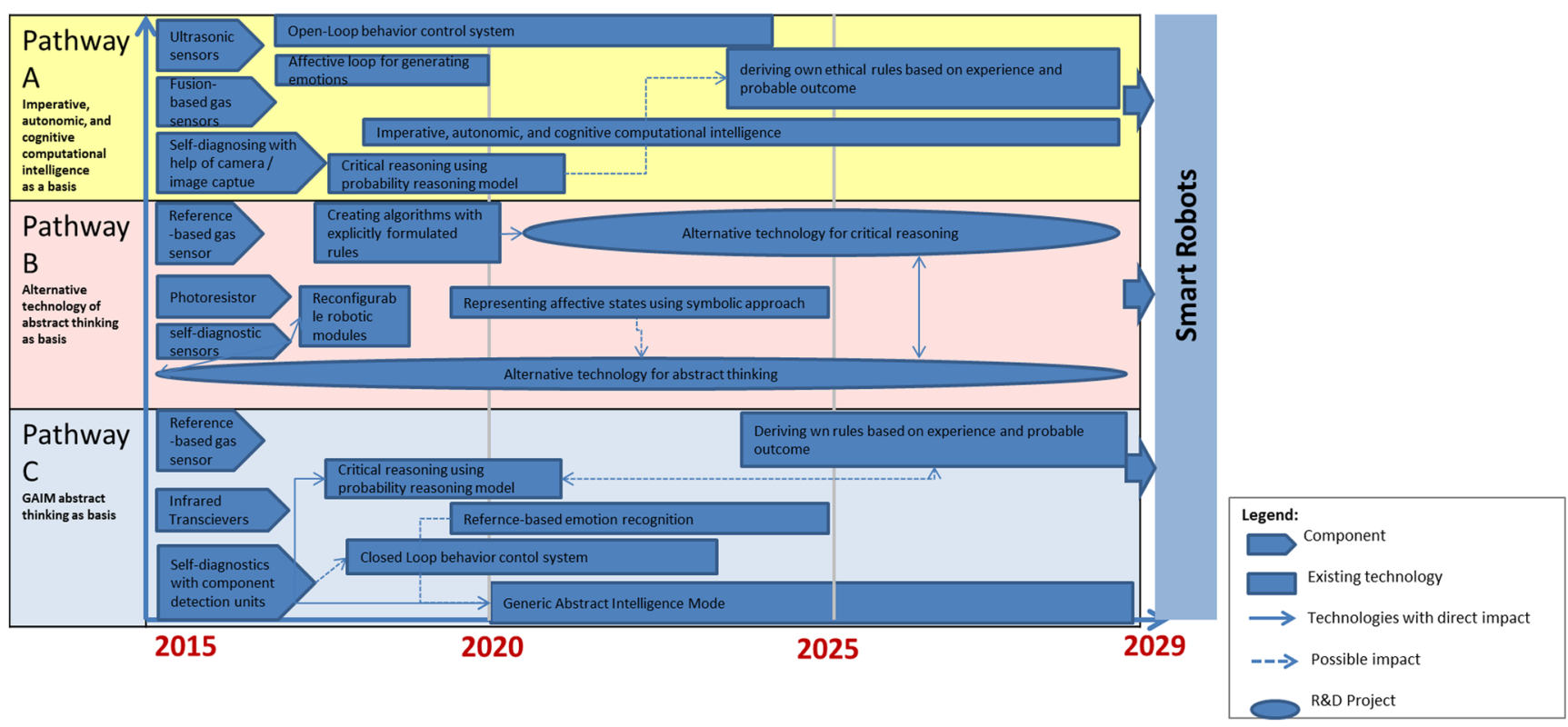

Fig. 3 Technology roadmaps representing three possible pathways for "smart robots by the year 2029" 
Pathway B is the most intensive option in terms of R\&D expenditures: a smart robot utilizes an alternative technology for abstract thinking. The $R \& D$ project aimed to develop this technology is scheduled to last ca. 10 years. To get the information about the environment the robot uses a number of sensors: the reference-based gas sensor enables the robot to smell (however, it is only capable of recognizing the odours that have been stored previously in its memory); photoresistors help it to orient itself in the environment; selfdiagnostic sensors located in all critical modules enable it to perform self test. In case of damage, the robot is able to diagnose the trouble autonomously and adjust its motions by reconfiguring its modules. It will generate emotions mostly through gestures and symbols. The second large $R \& D$ project envisaged for this pathway is targeted to create an alternative technology for critical reasoning. To make moral decisions the robot will be guided by explicitly formulated rules, insofar as the premises do not contradict to each other. Pathway B allows the creation of a more sophisticated smart robot; however, it implies relatively high $R \& D$ costs and certain risks related to a technology failure.

Pathway $\mathbf{C}$ depicts a robot using the generic abstract intelligence mode for its cognitive processes. It derives information about odours from reference-based gas sensors, uses infrared transceivers to detect obstacles. Being equipped with the closed-loop behaviour control system, the robot performs self-check autonomously with help of component detection units. To generate emotions the robot refers to its database with stored emotional states. Critical judgements are made using the probability-reasoning model. This model partially governs its ethical behaviour enabling it to derive its own moral rules based on experience and probable outcome. Pathway $\mathrm{C}$ describes a cost efficient model of a smart robot; however, special attention should be paid to algorithms for critical reasoning and ethical behaviour. Since the robot will act completely autonomously, it must be guaranteed it won't infringe basic norms and rules while taking a decision.

\section{Case study 2: GoPro Inc. - Kolor SAS.}

In this project, the objective was to capture and explore potential output technologies in the deal between GoPro Inc., a US-based manufacturer of digital cameras, and Kolor SAS, a virtual reality company from France. The acquisition amount has not been disclosed. Both companies have IP portfolios and continue operating in the market under their original names.

\section{GoPro's profile}

GoPro Inc., a US-American producer of high-tech action cameras, is currently expanding into foreign markets. The company (formerly known as Woodman Labs) was founded in 2002 by Nick Woodman with the purpose of producing image capture devices for athletes and extreme sport enthusiasts. The analysis of the deal has been performed in July-October 2015.

Over the past 10 years GoPro has shown a remarkable growth; an initial public offering was made in 2014. According to its financial statements for the fiscal year 2015, GoPro has achieved an impressive revenue expansion topping USD 1.6 bn showing $16 \%$ year-to-year growth (USD 1.4 bn in 2014, USD $985.7 \mathrm{mln}$ in 2013) [75]. Its R\&D expenditures for the last year made up USD $241.7 \mathrm{mln}$. To date, GoPro Inc. employs over 1,000 specialists around the globe.

By July 2015, GoPro Inc has reportedly closed three M\&A deals. All of the target companies contribute to GoPro's core business. With its earliest acquisition, Cineform, GoPro has extended its capabilities in video compression and processing; General Things Inc. equipped it with know-how in software for image editing and sharing. The acquisition of Kolor SAS, which lies in the focus of this study is aimed to add capabilities in panoramic viewing.

To retrieve data about GoPro's R\&D portfolio the following search strategy has been used:

STAN-ASSIGNEE ("GOPRO”) OR STAN-ASSIGNEE ("CINEFORM") OR STAN-ASSIGNEE ("WOODMAN $L A B S$ ")

As of August 30, 2015, GoPro and its affiliate companies held a portfolio of 156 patents with distinct clusters in camera housing, data compression, expansion module, camera management system and some other fields.

To get a better understanding of the company's intents, we went through its mission statements and future-oriented press releases. GoPro is striving to create a product line to help people capture dynamic photo and video footage. This idea is coupled with company's strategic goals of creating innovative capture devices that would enable online seamless content management, editing and sharing. These goals provide a clue to company's M\&A strategy.

\section{Profile of Kolor SAS}

The major competences of Kolor SAS lie in the sphere of panoramic viewing and virtual reality. Panoramic viewing is a technique of photo and/or video image capture based on the "wide format". Virtual reality is an interactive computerdriven replication of an environment targeted to simulate the imagined reality creating the effect of physical presence of an observer.

The market for panoramic viewing has been emerging for the last two decades and is currently driven by the following trends: advancements in appropriate devices and accessories for panoramic images capture; easy and user-friendly technologies for editing, processing, sharing and online streaming of panoramas; technologies for making seamless photos and videos. In general, seamless panorama stitching has been 
extensively developed for at least ten last years to include advancements in adjustment of light variations, exposure tone and shooting angles to make panoramas look realistic [76].

The virtual reality segment is driven by the idea of using 3D technologies to enable simulation of the effect of presence in a virtual tour.

Both of the above-mentioned segments face similar challenges: technology for precise image reconstruction for objects with complex morphology (e.g. mountain landscapes) [77]; development of efficient, easy, user-friendly image processing, editing, buffering and streaming software (for PCs, tables and mobile devices) which would support different operational systems [78].

We then referred to Kolor in order to understand the company's know-hows. Kolor SAS is a privately held company specializing in high quality processing and editing of photo and video images based on the technologies of panoramic viewing, virtual tour making and video-stitching. The company's product line is represented by four solutions: software to make panoramas; tools enabling creating, editing and sharing virtual tours (Panotour, Livepano and Panotour viewer); 360-deg video maker with Autopano video and Kolor eyes and image processing with Neutralhazer.

The IP portfolio of Kolor SAS is represented by 7 patents (data retrieved on July 13, 2015) with inventions in geometric image transformation, panoramic viewing \& photography and photo and video processing, editing \& sharing via the Internet. It is noteworthy, that most of the advancements in virtual reality and panoramic viewing are software-based and often not patented.

\section{Elaborating projections in deal GoPro Inc. - Kolor SAS}

In order to identify potential technologies for the deal we performed media content analysis at Google News Aggregator using the search strategy, as follows:

((GoPro AND Kolor) AND (future OR perspective OR envisage OR plan OR will OR wish))

As of July 27, 2015, a total of 998 hits have been found covering the following areas:

- Virtual reality device

- Content monetization

- Panoramic viewing with drones

Two of the above topics, "virtual reality device" and "panoramic viewing with drones", will require further innovation activities from the parties. Since GoPro has already introduced its spherical camera array for capturing VR video [79], this technology was excluded from the further analysis. We selected "panoramic viewing with drones" to illustrate the method. Panoramic viewing and surveillance is a rapidly growing application field for drones [78]. The market is still not saturated; legal restrictions for the use of drones in the most countries represent the major obstacle on the way to the product use. In 2015, GoPro announced it would launch its own drones with panoramic cameras in 2016 [80].

For this project, we had to embrace advancements in panoramic viewing with deeper understanding of civil drone technology and complexities that may arise as these technologies are combined in a single product.

Based on the content analysis of scientific literature listed on Primo, we detected 24 sub-technologies required to set up a drone with panoramic camera. Six of these technologies have not been mentioned in IP portfolios of involved parties and are deemed open:

- Terrestrial command and control centre for a drone;

- Obstacle avoidance technology for a drone;

- (Drone) wing technology;

- Take off/ landing technology for a drone;

- Drone engine;

- Power source.

Table 2 shows identified technological projections for the open technologies.

We used qualitative content analysis of scientific literature and patents to get information about technological projections. Some projections have been deliberately excluded from further analysis: for the "engine" technology the turbo-prop and turbo-jet/fan engines designed for High Altitude/Long Endurance UAVs were not considered on later stages, since these engines are normally used in heavy military drones only. In the "power source" technology we excluded nuclear reactors from our analysis since nuclear power is prohibited for private commercial use in most of the countries.

Cross-impact analysis helped us reveal strong negative correlation between the type of terrestrial command and control centre and alternative wing form; there is strong correlation between engines and power sources used and minor correlations between take off / landing technologies and wing form.

\section{Roadmapping raw pathways}

The raw pathways for "panoramic viewing with drones" have been anchored to the wing form to correspond with the official announcement of GoPro's CEO Nickolas Woodman who mentioned that GoPro would introduce its quadcopter in 2016 [80] (Fig. 4).

The three pathways represent each the possible combination for drones utilizing either rotary wings (Pathways A and $\mathrm{B}$, yellow and red lines, respectively) or hybrid wings (Pathway $\mathrm{C}$, blue line). In all the three pathways a drone uses vertical take-off / landing technology and is equipped with electric engines, which would provide power to the drone 
Table 2 Technological projections for open technologies for "panoramic viewing with drones"

\begin{tabular}{|c|c|c|c|c|c|}
\hline $\begin{array}{l}\text { 1. Terrestrial command and control } \\
\text { center }\end{array}$ & $\begin{array}{l}\text { 2. Obstacle avoidance } \\
\text { technology for drones }\end{array}$ & 3. Wing Form & $\begin{array}{l}\text { 4. Takeoff / } \\
\text { Landing } \\
\text { technology }\end{array}$ & 5. Engine & 6. Power source \\
\hline $\begin{array}{l}\text { Command and control using } \\
\text { Dynamic Data-Driven } \\
\text { Application System (DDDAS) }\end{array}$ & using potential fields & Fixed wing & Vertically & Electric & Fuel tanks \\
\hline $\begin{array}{l}\text { Dynamic model using frequency- } \\
\text { domain system identification } \\
\text { techniques }\end{array}$ & $\begin{array}{l}\text { Obstacle avoidance algorithm } \\
\text { based on the fluid mechanics } \\
\text { panel methods }\end{array}$ & Rotary wing & With a runway & Piston & $\begin{array}{l}\text { Batteries and } \\
\text { Accus }\end{array}$ \\
\hline H-infinity loop-shaping technique & using dynamic window approach & Tilt wing & Hybrid technology & Rotary & Fuel cells \\
\hline Linear quadratic (LQ) design methods & $\begin{array}{l}\text { Vision (optical flow)-based } \\
\text { obstacle avoidance }\end{array}$ & Hybrid form & Alternative & Turbo-prop & Photovoltaic \\
\hline L1 adaptive control & & & & Turbo-jet/fan & Nuclear \\
\hline $\begin{array}{l}\text { Neural network based adaptive } \\
\text { flight controller }\end{array}$ & & & & & \\
\hline
\end{tabular}

and a camera. Pathway B is designed to use fuel cells as a power source in order to increase the durability of the drone.

Figure 5 presents the three roadmaps for the project. The results consider the time horizon announced by GoPro's CEO Nickolas Woodman. Since technological projections are well developed, the project won't require huge R\&D expenditures.

\section{Reporting}

Pathway A represents a roadmap for a "classical" rotary-wing drone: it requires no special runway and can take off and land on any horizontal surface. The device can charge easily from the electric power network. The capacity of the drone depends on a type of accumulator / battery life and may achieve a maximum of $90 \mathrm{~min}$ of flying time. The DDDAS control system in combination with the obstacle avoidance technology based on dynamic window approach enables a dynamic control over the UAV ensuring that the system remains responsive during the entire flying time.

Pathway B is the most expensive alternative for a rotarywing drone, since the vehicle uses fuel cells as a power source. This technology enables considerably extended flying time of

\begin{tabular}{|c|c|c|c|c|c|c|}
\hline & $\begin{array}{l}\text { 1. Terresrial command and } \\
\text { control center }\end{array}$ & $\begin{array}{l}\text { 2. Obstacle } \\
\text { avoidance } \\
\text { technology for } \\
\text { drones }\end{array}$ & 3. Wing Form & $\begin{array}{l}\text { 4. Takeoff / } \\
\text { Landing } \\
\text { technology }\end{array}$ & 5Engine & 6. Power source \\
\hline Projec. 1 & $\begin{array}{l}\text { Command and control } \\
\text { using Dynamic Data-Driven } \\
\text { Application Sy stem } \\
\text { (DDDAS) }\end{array}$ & $\begin{array}{l}\text { using potential } \\
\text { fields }\end{array}$ & Fixed wing & Vertically & Electric & Fuel tanks \\
\hline Projec. 2 & $\begin{array}{l}\text { Dynamic model usıgg using } \\
\text { frequency-domain } s, \text { stem } \\
\text { identification techniqu ?s }\end{array}$ & $\begin{array}{l}\text { Woidance } \\
\text { lgorithm based } \\
\text { on the fluid } \\
\text { nechanics panfi } \\
\text { nethods }\end{array}$ & & & Pistc & $s$ and \\
\hline Projec. 3 & Hळloop-shaping technique & $\begin{array}{l}\text { using dyr amic } \\
\text { vindow } \\
\text { ap pr sach }\end{array}$ & Tilt wing & Hybrid technology & Rotary & \\
\hline Projec. 4 & $\begin{array}{l}\text { linear quadratic }(y) \text { design } \\
\text { methods }\end{array}$ & $\begin{array}{l}\text { Vision (optical } \\
\text { flow)-based } \\
\text { obstacle } \\
\text { avoidance }\end{array}$ & Hybrid form & Alternative & & Photovbltaic \\
\hline Projec. 5 & L1 adaptive control & & & & & \\
\hline Projec. 6 & $\begin{array}{l}\text { neural network based } \\
\text { adaptive flight controller }\end{array}$ & & & & & \\
\hline
\end{tabular}

Fig. 4 Raw pathways for "panoramic viewing with drones" 


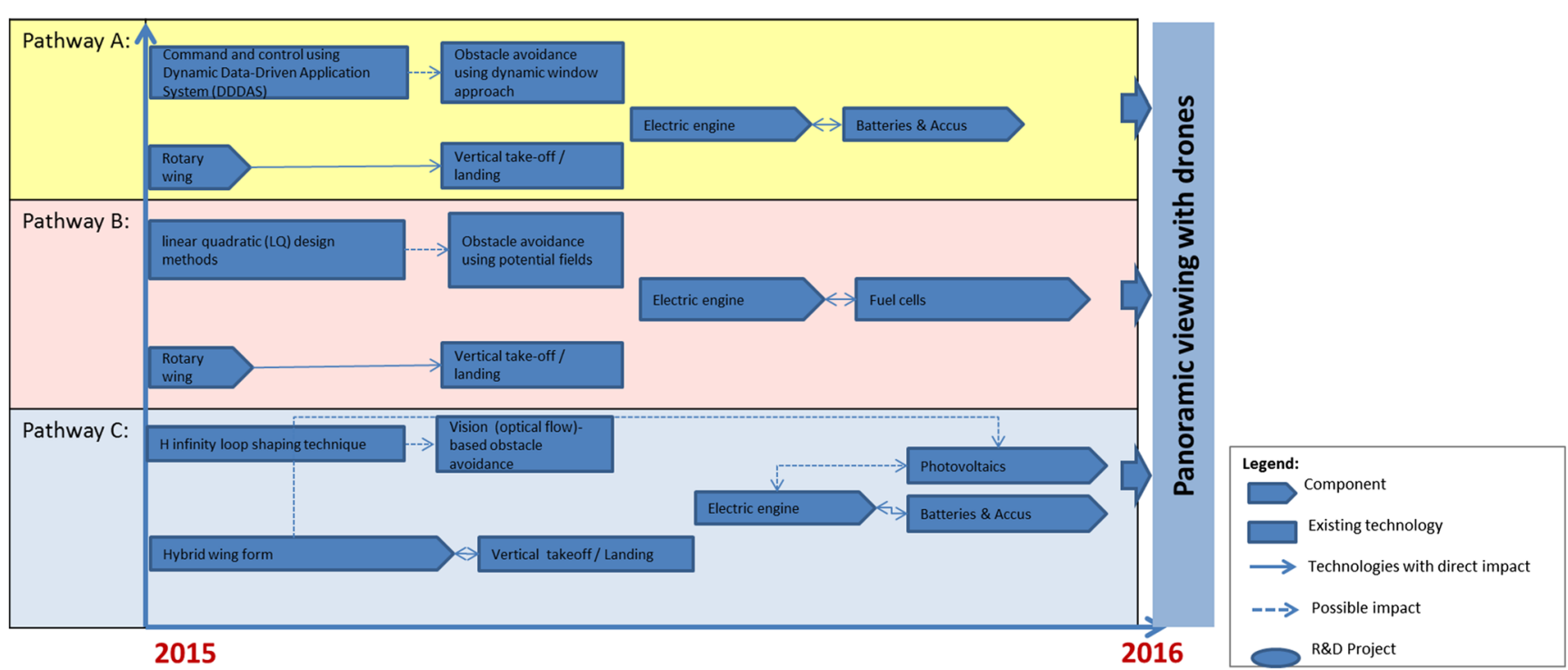

Fig. 5 Technology roadmaps for "panoramic viewing with drones"

the device (up to 4-h flying time), thus providing the possibility to shoot long videos without charging. The LQ design of control helps monitor internal and external environment during the flight and use the data to model safe flight trajectories based on potential fields.

Another way to extend the flying time of a UAV is shown in Pathway C. The hybrid wing design enables installation of photovoltaic modules on the wings that serve as an additional power source during the flight. This wing design ensures aerial stability and robustness of the UAV in unfavourable weather conditions; at the same time, the total mass of the device will increase. H-infinity loop shaping control ensures a responsive steering; video sensors enable monitoring of the environment in order to avoid obstacles in real-time.

\section{Discussion}

\section{Findings}

In this paper, we combined the approaches and techniques of innovation management and Futures Studies in a framework enabling a grounded outside-in assessment of company's images of potential innovation activities triggered by its closed merger and acquisition deal. The framework has been tested on several case studies involving both large concerns and SME, so that we could achieve commonality in the steps. It has been shown that information about the closed deal may be used as a trigger to initiate further research about possible outcome technologies. Information and data retrieved from publicly availably data banks provides a basis for grounded forecasts about upcoming innovation activities of the focal companies in a given technological field. Comparing data about trends, advancements and challenges in emerging technologies obtained from academic literature with patent data representing existing capabilities of involved companies help us identify open technologies that build part of an output technology. Developing capabilities in open technologies is likely to predetermine the innovation agenda of the focal companies in the given context.

The flexibility of assessment steps for the focal companies and building projections constitutes a basis for tailoring the framework for each specific case. This flexibility might be critical in cases when a focal company does not report its know-hows; when R\&D activities are outsourced and may not be evidently proven or if either party of a deal prefers not to disclose its corporate data.

Of key interest to us was first, to integrate quantitative media content analysis as well as basic techniques of text and data mining into the forecasting process; we consider that these sources of information contain a significant potential for future research, insofar as patent- and scientific literature data banks are publicly available, codified and constantly replenishable sources of knowledge. Appealing to the knowledgebased view on innovation activities, this paper contributes to the position that technological knowledge may represent the core interest in mergers and acquisitions [7] and signalize possible upcoming strategic shifts in involved companies [81]. This fact is especially important in case of growing technological complexity, since it enables inclusion of the deals into a broader technological context and helps unfold potential innovation activities of involved companies.

It has been shown, that the pathways must be considered in their integrity, as alternative and complementary trajectories of technological development, rather than separate roadmaps.

The results of this research can contribute to Futures Studies in several practical aspects. They can be used by the acquirers in the process of technology due diligence to 
evaluate business potential of the deal (the "make or buy" decision), assess whether or not "the deal is tied to the firm's overall strategy and will clearly advance the firm along its defined strategic path" [11], draft the value chain (such as materials and components used, suppliers thereof, potential users) of the upcoming technology, analyse synergy potential and risks and estimate costs and time required to develop or source the missing sub-technologies. The target companies can use the framework to highlight their strategic advantages and derive the value of a technology in each deal. Investors and private equity institutions can apply the method to track the market dynamics, get insights about possible strategic shifts of certain organizations, reveal potential disruptive technologies and factors that may impact industry attractiveness. Market competitors can benefit from the proposed approach by reconstructing the innovation architecture behind specific M\&A deals and thus reducing uncertainty about likely "next moves" of their rivals. The framework can also be used by regulatory authorities in developing policies and standards for emerging technologies, since it provides information about additional functionality and potential risks related to the focal technologies.

\section{Limitations and future research}

A considerable part of this research relies on the analysis of patent and M\&A data; the data banks used are global and publicly available online. At the same time, it is hardly possible to perform an assessment for other types of R\&D activities, such as software development or internal company's know-hows, since this knowledge is rarely codified. Besides this, there is a risk to omit R\&D activities and achievements that are not publicly reported, outsourced to third parties or not secured by a patent or other authorship rights.

In this paper, the focus lay on technological and forecasting aspects, which are essential for technology due diligence but might be insufficient for risk and costs assessment. Therefore, the proposed framework can be extended by standard financial tools of project assessment, like net present value analysis (NPV) or real options [1, 37].

The proposed framework has been designed to omit expert workshops. However, it is possible and would be desirable to make at least one workshop while building raw pathways in order to discuss and reflect the major challenges that the involved companies might face while developing the open technologies. An important output could be an innovation chain diagram depicting advancements, options and potential disruptions along the pathway, which could further on be used as a guideline in company's operational processes. Moreover, calling upon persons knowledgeable in innovation subjects might be vital to double-check our interpretations of possible innovative output of the M\&A deal.
The design of this research is limited to visualize possible future innovation pathways only. Thereby each M\&A deal has been treated as an isolated event. It would make sense to analyse them as a extension of existing paths (or a shift therefrom) in order to uncover companies' mid- and long-term solid intentions and/or grasp disruptions (where the forecasted pathways form new innovation avenues).

Designing innovative products might result in synergies of existing capabilities in R\&D. The proposed framework provides the possibility to outline possible novel application fields for focal technologies.

The proposed framework has shown good results in forecasting innovation activities trigged by M\&A deals; however, further research aimed at minimizing the above limitations can considerably extend functionality and accuracy of the proposed scheme of analysis.

Open Access This article is distributed under the terms of the Creative Commons Attribution 4.0 International License (http:// creativecommons.org/licenses/by/4.0/), which permits unrestricted use, distribution, and reproduction in any medium, provided you give appropriate credit to the original author(s) and the source, provide a link to the Creative Commons license, and indicate if changes were made.

\section{References}

1. Bannert V (2003) Technology sourcing via acquisitions - an integrated technology due diligence process. In: Tschirky H, Jung H-H, Savioz P (eds) Technology and innovation on the move. Verlag Industrielle Organisation, Zürich, pp 175-188

2. Vrande V, Vanhaverbeke W, Duysters G (2011) Technology insourcing and the creation of pioneering technologies. J Prod Innov Manag 28:974-987

3. Roush W (2012) Google's rules of acquisition: how to be an android, not an aardvark. IOP Xconomy. http://www.xconomy. com/san-francisco/2012/03/05/googles-rules-of-acquisition-howto-be-an-android-not-an-aardvark/. Accessed 31 Mar 2016

4. Pricewaterhousecoopers (2014) Hightech-Report Deutschland M\&A-Aktivitäten in der Hightech-Branche 2004 bis 2014. IOP Pricewaterhousecoopers. https://www.pwc-wissen. de/pwc/de/shop/publikationen/Hightech-Report+Deutschland\%2 C+MundA/?card=12811. Accessed 30 Mar 2016

5. EY (2014) Industrial mash-ups: a disruptive new partnering form will accelerate innovation - again. IOP ey. http://www.ey. com/Publication/vwLUAssets/ey-industrial-mash-ups/\$FILE/eyindustrial-mash-ups.pdf. Accessed 30 Mar 2016

6. Ledbetter D (2015) Why the ad tech industry is consolidating like crazy. IOP Venture beat. http://venturebeat.com/2015/04/13/whythe-ad-tech-industry-is-consolidating-like-crazy/. Accessed 30 Mar 2016

7. Farhadi M, Tovstiga G (2010) Intellectual property management in M\&A transactions. J Strat Manag 3:32-49

8. Riviezzo A (2013) Acquisitions in knowledge-intensive industries. Exploring the distinctive characteristics of the effective acquirer. Manag Res Rev 36(2):183-212

9. Bollen L, Vergauwen P, Schnieders S (2005) Linking intellectual capital and intellectual property to company performance. Manag Decis 43(9):1161-1185 
10. Rossi M, Yedidia S, Amos T (2013) Mergers and acquisitions in the hightech industry: a literature review. Int J Organ Anal 21(1):66-82

11. Morrissette S (2013) A framework for validating an M\&a deal thesis. J Account Finance 13(2):75-87

12. Huang L, Guo Y, Peng Z, Porter A (2011) Characterizing a technology development at the stage of early emerging applications: nanometrical-enhanced biosensors. Technol Anal Strateg Manag 23:527-544

13. Robinson D, Propp T (2008) Multi-path mapping for alignment strategies in emerging science and technologies. Technol Forecast Soc 75:517-538

14. Porter A, Ashton W, Clar G, Coates J, Cuhls K, Cunningham S et al (2004) Technology futures analysis: toward integration of the field and new methods. Technol Forecast Soc 71(3):287-303

15. Robinson D, Huang L, Guo Y, Porter A (2013) Forecasting innovation pathways (FIP) for new and emerging science and technologies. Technol Forecast Soc 80:267-285

16. Cuhls K (2011) Schnittstellen von Foresight und Innovationsmanagement. In: Tiberius V (ed) Zukunftsorientierung in der Betriebswirtschaftslehre. Gabler, Wiesbaden, pp 189-199

17. Cartwright S, Schoenberg R (2006) Thirty years of mergers and acquisitions research: recent advances and future opportunities. $\mathrm{Br}$ J Manag 17:1-5

18. Steger U, Kummer C (2007) Why merger and acquisition (M\&A) waves reoccur - the vicious circle from pressure to failure. IOP IMD International. https://www.imd.org/research/publications/ upload/Steger_Kummer_WP 2007 11.pdf. Accessed 17 Mar 2016

19. Pricewaterhousecoopers (2013) US technology M\&A insights. IOP Pricewaterhousecoopers. http://www.pwc.com/en US/us/transaction-services/publications/assets/pwc-us-technologymergers-acquisitions.pdf. Accessed 30 Mar 2016

20. Harding D, Henderson S (2013) Decade of plenty for M\&A kings. IOP Bain \& Company. http://www.bain.com/publications/ articles/decade-of-plenty-for-m-and-a-kings-financial-review.aspx. Accessed 11 Mar 2016

21. Littley J (2001) Buying knowledge: an examination of mergers and acquisitions as tools for competency growth in technology firms. Dissertation, George Washington University

22. Hitt M, Hoskisson R, Ireland D, Harrison J (1991) Effects of acquisitions on R\&D inputs and outputs. Acad Manag J 34:693-707

23. Hitt M, King D, Krishnan H, Makri M, Schijven M, Shimizu K et al (2009) Mergers and acquisitions: overcoming pitfalls, building synergy, and creating value. Bus Horiz 52:523-529

24. Graebner M, Eisenhardt K, Roundy P (2010) Success and failure in technology acquisitions: lessons for buyers and sellers. Acad Manag Perspect 24:73-92

25. Helfat C (2007) Dynamic capabilities: understanding strategic change in organizations. Blackwell, Oxford

26. Alvarez S, Barney J (2001) How entrepreneurial firms can benefit from alliances with large partners. Acad Manag Exec 15:139-148

27. Felenbok J-P, Shankar S, Varma S (2013) Analysis: in M\&A the rewards, and risks, are high. IOP Bain \& Co. http://www.bain. $\mathrm{com} /$ publications/articles/analysis-in-m-and-a-the-rewards-andrisks-are-high.aspx. Accessed 29 Mar 2016

28. Garud R, Nayyar P (1994) Transformative capacity: continual structuring by intertemporal technology transfer. Strateg Manag J 15:335-368

29. Benou G, Madura J (2005) High-tech acquisitions, firm specific characteristics and the role of investment bank advisors. J High Tech Manag Res 16(1):101-120

30. Cummings J, Teng B-S (2003) Transferring R\&D knowledge: the key factors affecting knowledge transfer success. J Eng Technol Manag 20(1):39-68

31. Nonaka I, Kodama M, Hirose A, Kohlbacher F (2014) Dynamic fractal organizations for promoting knowledge-based transformation - a new paradigm for organizational theory. Eur Manag J 32(1):137-146

32. Takeuchi H (2013) Knowledge-based view of strategy. Universia Bus Rev 40:68-79

33. Argote L, Miron-Spektor E (2011) Organizational learning: from experience to knowledge. Organ Sci 22(5):1123-1137

34. Sveiby K, Lloyd T (1987) Knowhow company. Add value by valuing creativity. Bloomsbury, London

35. Teece D (2000) Strategies for managing knowledge assets: the role of firm structure and industrial context. Long Range Plan 33:35-54

36. Peršič A, Markič M (2011) The impact of social responsibility, vision and strategy on successful corporate operations. Manag Glob Transit 11(1):27-40

37. Bannert V, Tschirky H (2004) Integration planning for technology intensive acquisitions. R\&D Manag 34:481-496

38. Chesbrow H (2003) The era of open innovation. MIT Sloan Manag Rev 1:35-41

39. Angwin D, Vaara E (2005) Introduction to the special issue. 'Connectivity' in merging organizations: beyond traditional cultural perspectives. Organ Stud 26(10):1445-1453

40. Ansoff I, Steward J (1967) Strategies for a technology-based business. Harv Bus Rev 45(6):71-83

41. Mintzberg H (1994) The rise and fall of strategic planning. Prentice Hall, New York

42. Mintzberg H (1995) Die Strategische Planung. Aufstieg, Niedergang und Neubestimmung. Hanser, München

43. Schreyögg G (1999) Strategisches Management: Entwicklungstendenzen und Zukunftsperspektiven. Unternehmung 53:387-407

44. Mintzberg H (1999) Strategy Safari. Eine Reise durch die Wildnis des strategischen Managements. Ueberreuter, Wien

45. Neuhaus C, Minx E (2009) Die Zukunft ist anders: Extrapolation und Konstanzannahmen als Instrumente und Fallstricke der Zukunftsschau. In: Reimer M, Fiege S (eds) Perspektiven des Strategischen Controllings. Gabler, Wiesbaden, pp 229-237

46. Neuhaus C (2006) Zukunft im Management: Orientierungen für das Management von Ungewissheit in strategischen Prozessen. Systematische Forschung im Karl-Auer Verlag, Heidelberg

47. Fleming L (2001) Recombinant uncertainty in technological search. Manag Sci 47(1):117-132

48. Coates V, Farooque M, Klavans R, Lapid K, Linstone H, Pistorius $\mathrm{C}$ et al (2001) On the future of technological forecasting. Technol Forecast Soc 67:1-17

49. Bergek A, Jacobsson S, Carlsson B, Lindmark S, Rickne A (2007) Analyzing the functional dynamics of technological innovation systems: a scheme of analysis. Res Policy 37:407-429

50. Coates J, Mahaffie J, Hines A (1994) Technological forecasting: 1970-1993. Technol Forecast Soc 47:23-33

51. Armstrong $J$ (1978) Long-range forecasting: from crystall ball to computer. Wiley, New York

52. Watts R, Porter A (1997) Innovation forecasting. Technol Forecast Soc 56:25-47. doi:10.1109/PICMET.1997.653329

53. Makridakis S, Wheelwright S, Hyndman R (1998) Forecasting methods and applications, 3rd edn. Wiley, New York

54. Kappel T (2001) Perspectives on roadmaps: how organizations talk about the future. J Prod Innov Manag 18(1):39-50

55. Lee S, Park Y (2005) Customization of technology roadmaps according to roadmapping purposes: overall process and detailed modules. Technol Forecast Soc 72:567-583

56. Groenveld P (1997) Roadmapping integrates business and technology. Res Technol Manag 40(5):48-55

57. Porter A, Detampel M (1995) Technology opportunities analysis. Technol Forecast Soc 49(3):237-255

58. Zhu D, Porter A (2002) Automated extraction and visualization of information for technological intelligence and forecasting. Technol Forecast Soc 69:495-506 
59. Häder M (2014) Delphi-Befragungen: ein Arbeitsbuch. Springer Fachmedien, Wiesbaden

60. Montecchi T, Russi D, Liu Y (2013) Searching in cooperative patent classification: comparison between keyword and concept-based search. Adv Eng Inform 27:335-345

61. Steidl P, Emery G (1997) Corporate image and identity strategies: designing the corporate future. Business \& Professional Publishing, Sydney

62. Kurzweil R (1999) The age of spiritual machines: when computer exceed human intelligence. Viking, New York

63. Dowing G, Weeks W (2011) Media analysis: what is it worth? J Bus Strateg 32(1):26-33

64. Bañuls V, Turoff M, Hiltz S (2013) Collaborative scenario modeling in emergency management through cross-impact. Technol Forecast Soc 80(9):1756-1774

65. Yoon B, Park Y (2005) A systematic approach for identifying technology opportunities: keyword-based morphology analysis. Technol Forecast Soc 72:145-160

66. Alphabet Inc. Investor relations (2016) Form 10-Q. IOP Alphabet Inc. https://abc.xyz/investor/pdf/20150331_google_10Q.pdf. Accessed 13 July 2016

67. Roberts J (2014) Google paid \$4B for patents: why the motorola deal worked out just fine. IOP gigaom. https://gigaom.com/2014/01 /30/google-paid-4b-for-patents-why-the-motorola-deal-workedout-just-fine/. Accessed 6 July 2016

68. Google Inc. (2016) Ten things we know to be true. IOP Google Inc. https://www.google.com/about/company/philosophy/. Accessed 14 July 2016

69. Chu B, Jung K, Han C-S, Hong D (2010) A survey of climbing robots: locomotion and adhesion. Int J Precis Eng Manuf 11(4): 633-647

70. Berring J, Kianfar K, Lira C, Menon C, Scarpa F (2010) A smart hydraulic joint for future implementation in robotic structures. Robotica 28:1045-1056
71. Rozo L, Jimenez P, Torra C (2010) Sharpening haptic inputs for teaching a manipulation skill to a robot. In: 1st IEEE International Conference on Applied Bionics and Biomechanics. Venice, pp $331-340$

72. Yakub F, Khudzairi A, Mori Y (2014) Recent trends for practical rehabilitation robotics, current challenges and the future. Int $\mathrm{J}$ Rehabil Res 37(1):9-21

73. Wang Y (2012) The cognitive mechanisms and formal models of consciousness. Int J Cogn Inform Nat Intell 6(2):23-40

74. Khomami N (2014, February 22) 2029: the year when robots will have the power to outsmart their makers. The Guardian

75. GoPro Inc. (2015) GoPro Announces Fourth Quarter and Full Year 2015 Results. IOP GoPro. http://investor.gopro.com/releasedetail. $\mathrm{cfm}$ ?releaseid=953247. Accessed 13 July 2016

76. Warg G (2006) Hiding seams in high dynamic range panoramas. In: Applied perception in graphics and visualization: Proceedings of the 3rd symposium (APGV'06). pp. 150

77. Jazayeri I, Rajabifard A, Kalantari M (2014) A geometric and semantic evaluation of 3D data sourcing methods for land and property information. Land Use Policy 36:219-230

78. Eremia C-V, Neculoiu G, Grigoriu O, Oboukhova N, Motuko A (2013) Data compression and panoramic images formation in UAV military TV-monitoring system. Eur Sci J 9(33):436-449

79. GoPro Inc. (2015) GoPro spherical: drifting with the new $360^{\circ}$ camera array. IOP YouTube. https://www.youtube.com/watch?v= jbA4oEHleg8. Accessed 3 Sept 2015

80. GoPro Inc. (2015, 05 27) Nick Woodman talks virtual reality and drones. IOP GoPro. http://de.gopro.com/news/nick-woodmantalks-virtual-reality-and-drones. Accessed 3 July 2016

81. Subramaniam M, Youndt M (2005) The influence of intellectual capital on the types of innovative capabilities. Acad Manag J 48(3):450-463 